\title{
Pore-scale investigation of the effect of connate water on water flooding behavior
}

\author{
Arief SETIAWAN*, Tetsuya SUEKANE**, Yoshihiro DEGUCHI* and Koji KUSANO* \\ ${ }^{*}$ Department of Mechanical Engineering, The University of Tokushima \\ 2-1 Minamijyosanjima, Tokushima 770-8506, Japan \\ E-mail: ars_wa2@yahoo.co.id \\ ${ }^{* *}$ Department of Energy Sciences, Tokyo Institute of Technology \\ 4259 Nagatsuta-cho, Midori-ku, Yokohama, Kanagawa 226-8503, Japan
}

Received 13 March 2014

\begin{abstract}
Water flooding is one of the most important processes in oil production. Water is injected into an oil reservoir to maintain the reservoir's pressure and sweep some of the oil toward the production well. In an actual oil reservoir, in situ water, or connate water, is usually present and significantly impacts the water flooding process. We developed a visualization scheme utilizing a microfocused X-ray CT scanner to three-dimensionally observe the effects of connate water during water flooding at the pore scale. The water phase was injected upward into packed glass beads containing an oil phase both with and without connate water, and the process was scanned every minute until steady state was reached. Three-dimensional images were then constructed from X-ray CT data to clearly show the phenomena. Connate water significantly reduces oil recovery. In the porous medium without connate water, water flooding was able to produce approximately 1.5 times more oil than in the medium with connate water because of steadier interface movement. When injected water came in contact with connate water, the displacement front suddenly expanded into the pores containing connate water, thereby creating a jump-like movement leading to fingering. The pressure gradient between the inlet and outlet forced water to select the shortest route to the outlet. Water reached the outlet earlier when connate water exists. Short-circuiting due to fingering leads to formation of entrapped oil pockets and oil recovery yields.
\end{abstract}

Key words : Visualization, Imbibition, Oil trapping, Connate water, X-ray CT scanner

\section{Introduction}

Water flooding is one of the most important processes in oil production. Water is injected into an oil reservoir to maintain the reservoir pressure, and the water sweeps some of the oil toward the production well. In the water flooding process, water displaces oil, a higher viscosity fluid, creating an unstable interface. Local heterogeneities in the porosity and permeability of the porous medium may enhance interface instability causing premature breakthrough of the displacing fluid at the exit of the porous medium and the displacing fluid flows preferentially through that established path. In actual oil reservoirs, in situ water, or connate water, is usually found. The existence of connate water also significantly affects water flooding and tends to reduce oil recovery by enhancing the instability of the displacement front. Usually less than $50 \%$ of the original oil in a reservoir can be recovered by water flooding. Capillary pressure holds trapped oil in pore spaces.

Numerous laboratory studies have been conducted to observe the water flooding phenomena with and without the presence of connate water. Some studies suggest that connate water adds additional perturbations to the displacement front, causing more irregular water fingering in oil-wet porous medium during water flooding (Paterson et al., 1984; Jamaloei et al., 2010). During water flooding, the connate water is displaced from the core and connate water bank 
accumulation is formed in front of the injected water, thus affecting invasion patterns (Graue et al., 2012). Connate water displaces in a piston-like displacement during spontaneous imbibition (Graue and Ferno, 2011). However, pore-scale description of connate water effects during water flooding in a three-dimensional (3D) porous medium is still unclear and our understanding is limited.

Observation of water flooding at the pore-scale is usually conducted using micromodels (Chang et al., 2009; Jamaloei et al., 2010) or simulations (Blunt and King, 1992; Blunt and Scher, 1995; Fenwick and Blunt, 1998; Kang et al., 2004). Micromodels describe the water flooding process in two dimensions, and water flooding simulations require many parameters to be precisely determined. The recent development of microfocused X-ray computed tomography (CT) scanner technology allows nondestructive visualization of the phenomenon (Kumar et al., 2010), and the technique's application allows observations critical to our understanding of fluid transport.

This paper discusses the effect of the existence of connate water on water flooding and oil trapping processes through a bed of packed glass beads by scanning the processes using a microfocused X-ray CT scanner. Water flooding experiments were conducted in a water-wet porous medium. The time-dependent processes, including the initial state, initiation of water invasion, invasion pattern, and trapping phenomena, were visualized clearly and step-by-step at the pore scale. The effect of connate water on residual oil saturation and local velocity of oil were also estimated.

\section{Experiments}

\subsection{Experimental Scheme}

Water flooding was visualized using a microfocused X-ray CT scanner (ScanXmate-G100S110; Comscantechno Co.). Recent developments in high-resolution X-ray CT scanners have enabled us to directly observe porous structures (Al-Raoush and Willson, 2005). The image resolution depends on the ratio of the distances between the X-ray source, detector, and object. The X-ray CT scanner produced images in gray scales, whose intensity is proportional to X-ray absorption. For the oil and water phases, iodododecane doped with $23 \mathrm{wt} \%$ dodecane and distilled water were used, respectively. The properties of these phases are listed in Table 1. Glass beads fabricated from silica fibers with diameters of 350-500 $\mu \mathrm{m}$ (average $400 \mu \mathrm{m}$ ) were used in this experiment. The glass beads were washed with toluene, ethanol, and then water to remove the coating so that the glass beads became water-wet.

Table1 Properties of fluids

\begin{tabular}{llcc}
\hline Fluids & Composition & Density, $\mathrm{g} / \mathrm{cm}^{3}$ & Viscosity, mPa $\mathrm{s}$ \\
\hline Water & Distilled water & $0.998^{\mathrm{a}}$ & $1.002^{\mathrm{b}}$ \\
Oil & Iodododecane $77 \mathrm{wt} \%+$ dodecane $23 \mathrm{wt} \%$ & $1.031^{\mathrm{a}}$ & $3.110^{\mathrm{c}}$ \\
\hline
\end{tabular}

${ }^{\mathrm{a}}$ Measured at $20^{\circ} \mathrm{C}$

${ }^{\mathrm{b}}$ (Kestin et al. 1978)

${ }^{\mathrm{c}}$ Measured with falling ball viscometer at $20^{\circ} \mathrm{C}$

For the control experiment without connate water, a tube with an inner diameter of $10 \mathrm{~mm}$ and height of $60 \mathrm{~mm}$ was filled with oil, and the glass beads were gradually poured into it to avoid entrapping air. The section located in the middle of the tube, at a height of $10 \mathrm{~mm}$, was the observed area; this area was scanned before beginning water flooding to determine initial conditions. Water was then injected upward at a capillary number $\mathrm{Ca}=4.9 \times 10^{-7}$ and the beads were scanned every $5 \mathrm{~min}$ for $1 \mathrm{~h}$. With such a $\mathrm{Ca}$, water invasion process can be captured by X-ray CT scanner step-by-step at the pore scale in each time interval and total amount of injected water was more than 2 pore volumes.

For the experiments in the presence of connate water, a tube with an inner diameter of $10 \mathrm{~mm}$ and height of $60 \mathrm{~mm}$ was filled with water, and the glass beads were poured slowly into it. Oil was then injected upward at $\mathrm{Ca}=2.4 \times 10^{-6}$ for $1 \mathrm{~h}$, invading pores previously occupied by water. In this way, some water was entrapped, creating connate water for this experiment. The observed area was the same as described above and scanning began once the oil reached the outlet but before water flooding began. Water flooding was then conducted by injecting water upward at $\mathrm{Ca}=4.9 \times$ $10^{-7}$ and the beads were scanned every $5 \mathrm{~min}$ for $1 \mathrm{~h}$. The experimental setup is shown schematically in Fig. 1 . The capillary number, $\mathrm{Ca}$, is defined as the ratio of the viscous force to the capillary force at the pore scale (equation 1).

$$
\mathrm{Ca}=\frac{\mu V}{\gamma}
$$


where $V$ is the displacing phase velocity, $\mu$ is the water viscosity, and $\gamma$ is the interfacial tension between the oil and water. The water invasion velocity was $1.1 \times 10^{-5} \mathrm{~m} / \mathrm{s}(0.95 \mathrm{~m} /$ day $)$. The interfacial tension between water phase and oil phase was $22.5 \mathrm{mN} / \mathrm{m}$, as measured by the pendant drop method. At capillary numbers below $10^{-6}$, the trapping mechanism is dominated by capillary forces, and the viscous force can be neglected (Morrow and Songkran, 1981).

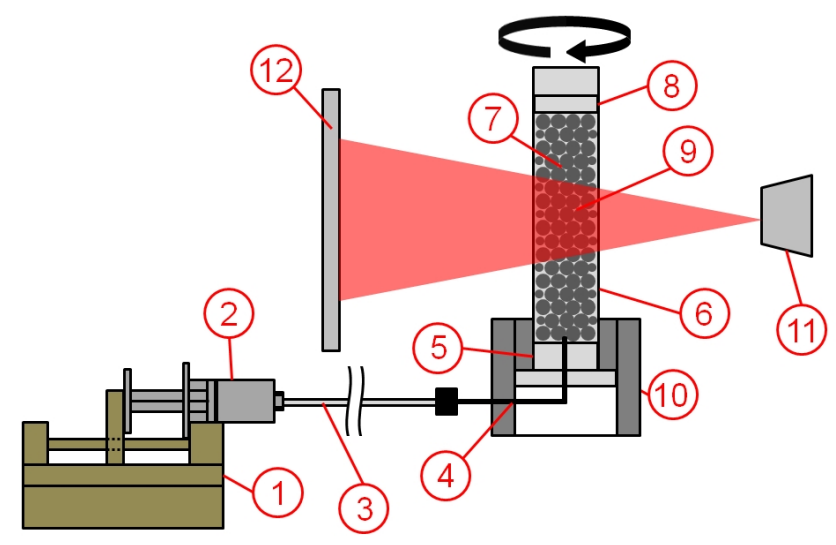

Fig. 1 Experimental setup. (1) Syringe pump, (2) syringe, (3) tubing, (4) needle, (5) bottom cap, (6) resin tube, (7) glass beads, (8) filter, (9) observed area, (10) holder, (11) X-ray source, (12) X-ray detector.

\subsection{Image Processing}

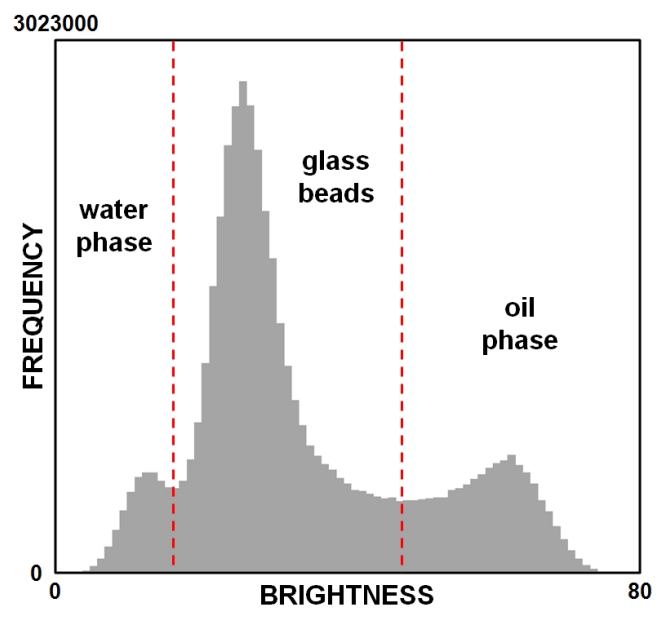

Fig. 2 Brightness intervals in the gray-scale images.

The maximum image resolution was $9.484 \mu \mathrm{m} / \mathrm{pixel}$, and the scale, boundary, and optimum brightness were set using the image processing software Image J (Abramoff et al., 2004). The glass beads, water, and oil were distinguished using appropriate brightness threshold values for each phase as shown in Fig. 2. Images from the image processing software were used to construct 3D images using the volume rendering software VG Studio Max 2.1. Images obtained at the initial conditions (in case of the experiment without connate water) or conditions after the water-filling process (in case of the experiment with connate water) were used to construct the glass bead structures for all data. Images from each time interval were used to digitally extract the water and oil phases independently. The glass bead structure was then combined with the water and oil phase images to create a complete structure at each time interval. Each phase can be digitally removed, if required.

Oil and water phases were carefully selected with two aims: to limit the buoyancy effect between the oil and water phases and to achieve the oil phase brightness such that the glass bead brightness lies between the oil and water brightnesses. A major consideration was placed on the X-ray broadening effect. In images, the interface is broadened, creating a slope-like shape, decreasing the accuracy with which the boundary can be located, especially when phenomena in a single pore space are being observed. If the phase brightnesses are in the order water $<$ oil $<$ glass beads, broadening of the interface between the water and glass beads creates the illusion of an oil film on the surface of 
the glass beads. To eliminate this, each image set should have a reference image subtracted in order to digitally separate the oil and water phases. However, this is time consuming and leads to another error caused by improper subtraction, because of irregularities in the image sets.

\section{Results and Discussion}

\subsection{Effect of Connate Water in Residual Oil Saturation}

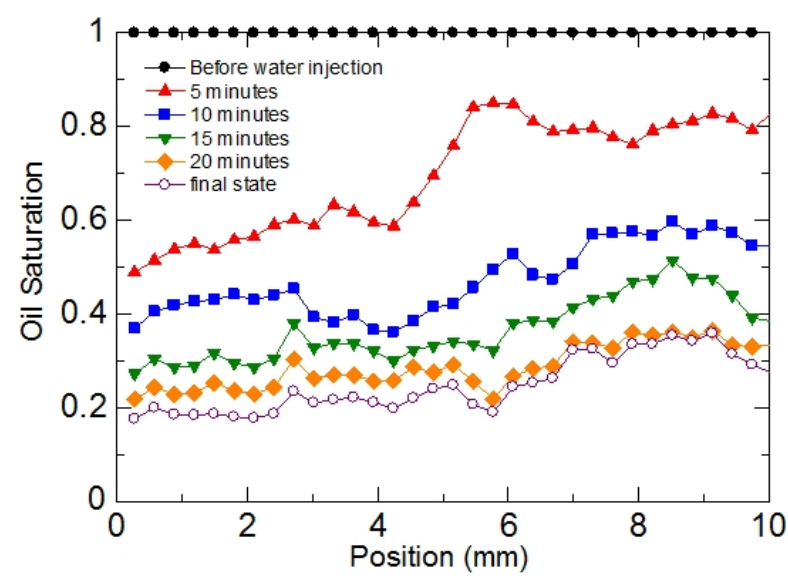

(a)

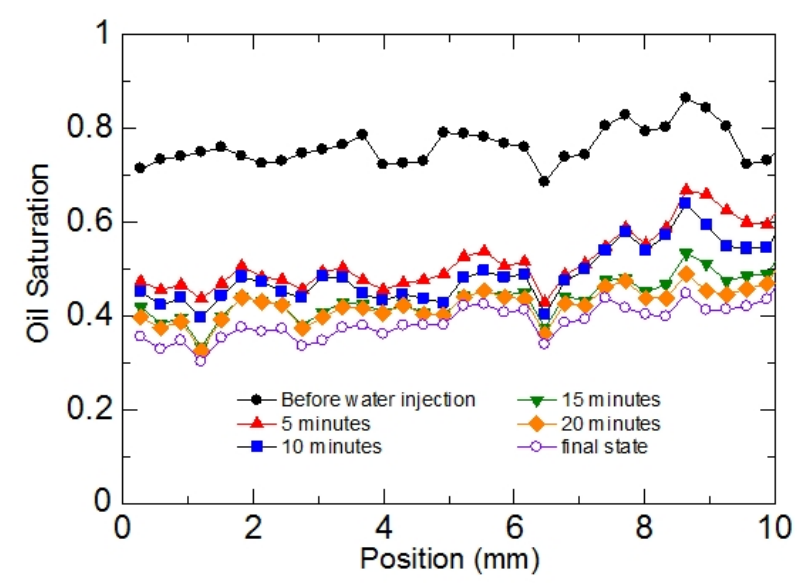

(b)

Fig. 3 Oil saturation change in porous medium during water flooding (a) without connate water and (b) with connate water.

Figure 3 shows the decrease in oil saturation during water injection. The presence of connate water reduces oil recovery significantly. In case of the porous medium without connate water, average residual oil saturation was $24.67 \%$ (Fig. 3a). Oil saturation decreases gradually until steady state is reached, indicating stability of the displacement front. Steady state occurs when the oil saturation of that particular time has no difference with oil saturation from previous time interval at any position along the tube. In case of the porous medium with connate water, reduction of oil saturation is dramatic (Fig. 3 b). In the beginning, connate water saturation was $23.87 \%$. After water flooding, average oil saturation reduced to $38.52 \%$. When water first invades the porous medium containing connate water during water flooding, interstitial water hastens water-front progression, resulting in significant reduction of oil saturation within 5 min. When one water finger reaches the outlet, the pressure gradient along this water finger significantly decreases. At that point, oil saturation is barely reduced until steady state is reached.

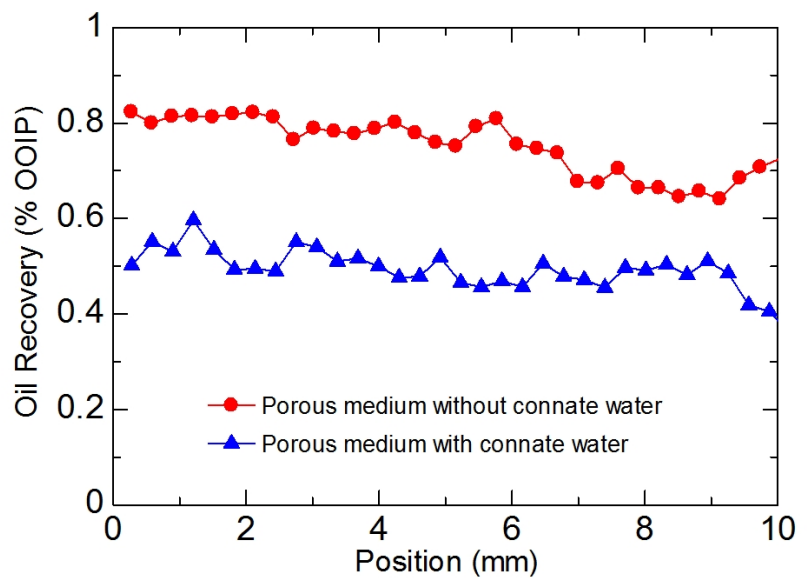

Fig. 4 Oil recoveries during water flooding in porous medium with and without connate water.

Figure 4 shows a comparison of oil recovery during water flooding for both porous media. Average oil recoveries in porous medium with and without connate water were $49.41 \%$ and $75.33 \%$ of the original oil, respectively. Clearly, the presence of connate water reduces oil recovery significantly. 


\subsection{Effect of Connate Water in Local Velocity of Oil}

From Fig. 3, the oil saturation of each position from each time interval was obtained. From that data, by applying the law of conservation of mass, the local velocity of oil at any distance from the inlet can be obtained. Change of local velocity of oil between two time intervals indicates how water displaces oil. Interpretation of the pattern gives a clue of the stability of water displacement front. We apply a material balance approach (Goodfield et al., 2001), which can be expressed as

$$
U_{o i l}(z, t)=U(t) F_{o i l}^{i n j}(t)-\frac{\partial V_{o i l}(z, t)}{\partial t}
$$

where $U_{o i l}(z, t)$ is the local velocity of oil in the z position and at time $\mathrm{t}, U(t)$ is the total fluid injection velocity in the inlet, and $F_{o i l}^{i n j}(t)$ is the fraction of oil in the inlet at time t. Oil volume per unit cross-sectional area between the packed glass beads and position $\mathrm{z}, V_{\text {oil }}(z, t)$, is defined by

$$
V_{\text {oil }}(z, t)=\int_{0}^{z} \phi(\zeta) S_{\text {oil }}(\zeta, t) d \zeta
$$

where $\phi(\zeta)$ is the porosity of the porous media in specific positions and $S_{o i l}(\zeta, t)$ is the oil saturation in specific positions at time $t$. Thus, the local velocity of oil at time $t$ in specific positions can be summarized as follows:

$$
U_{\text {oil }}(z, t)=\frac{V_{\text {oil }}(z, t)-V_{\text {oil }}(z, t+\Delta t)}{\Delta t}
$$

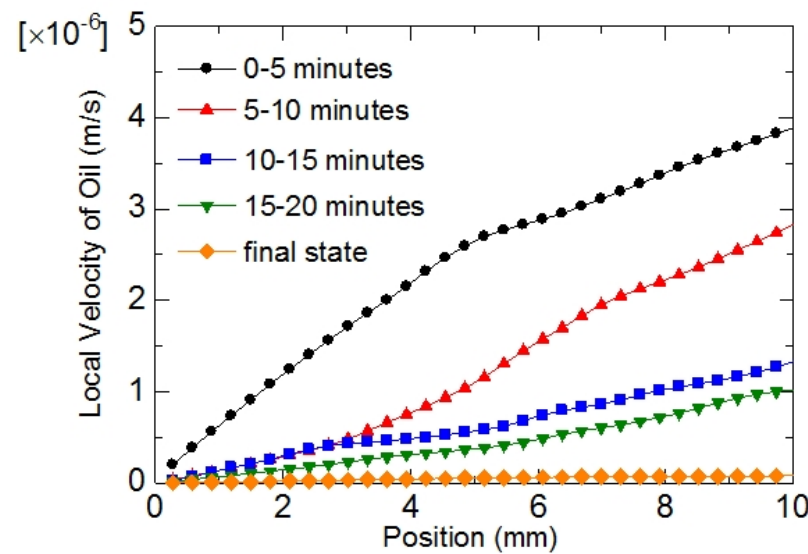

(a)

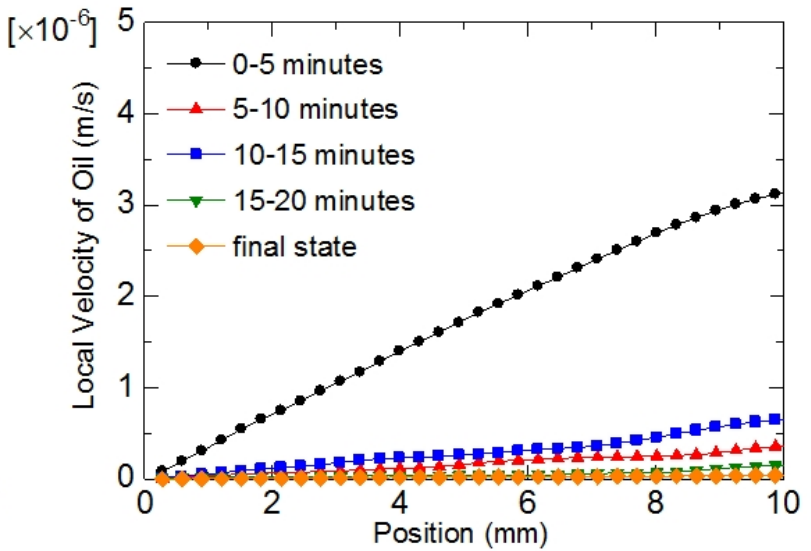

(b)

Fig. 5 Local velocity of oil in porous medium during water flooding (a) without connate water and (b) with connate water.

The local velocity of oil between two time intervals can be calculated from the saturation data using Eq. 4 . The results are shown in Fig. 5. During injection of water into the porous medium without connate water, the local velocity of oil gradually reduces as the water invades the pore space (Fig. 5a); this is due to the steady interface movement. In case of the porous medium with connate water, the local velocity of oil reduces dramatically (Fig. 5b). When injected water comes into contact with connate water, the displacement front rapidly moves to the other end of pores containing connate water, which causes a jump-like movement of water. This phenomenon helps water to move faster and reach the outlet earlier than that in the porous medium without connate water. Consequently, in the same period of time, the amount of oil moved by water is less in the porous medium with connate water, leading to lower local oil velocity. Because of the jump-like movement in the porous medium with connate water, water breaks through within 0-5 min after the initiation of water flooding, and therefore, the local velocity of oil decreases significantly. This indicates that after water breakthrough, only a small amount of oil is produced. An oil velocity of $0 \mathrm{~m} / \mathrm{s}$ indicates that oil has already been trapped. 


\subsection{Effect of Connate Water in Water Invasion Pattern}

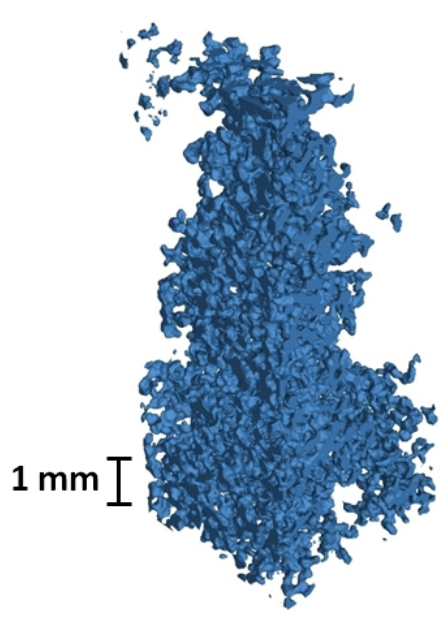

(a)

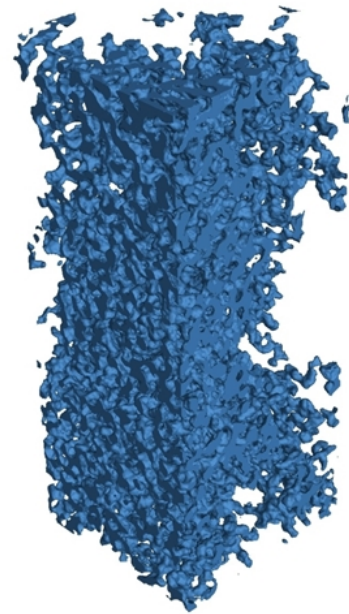

(b)

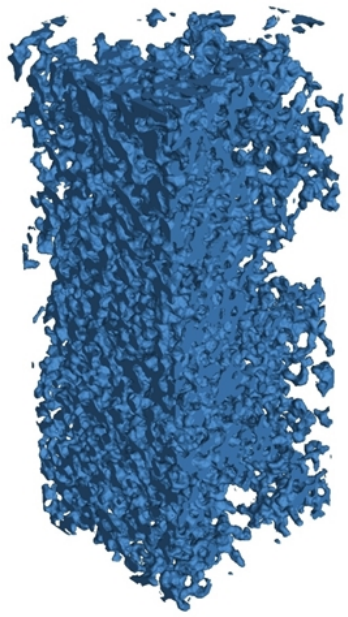

(c)

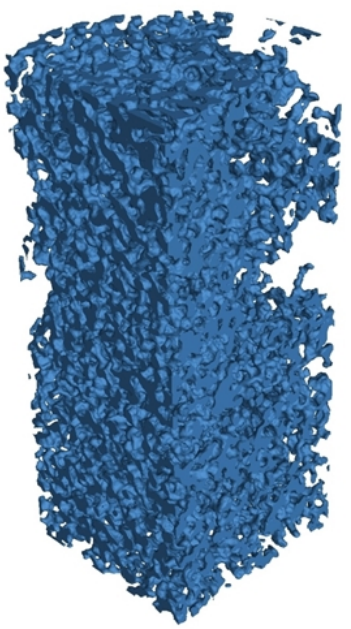

(d)

Fig. 6 Three-dimensional image of water flooding in porous medium without connate water. Following water injection for (a) $5 \mathrm{~min}$, (b) $10 \mathrm{~min}$, (c) $15 \mathrm{~min}$, and (d) at steady state.
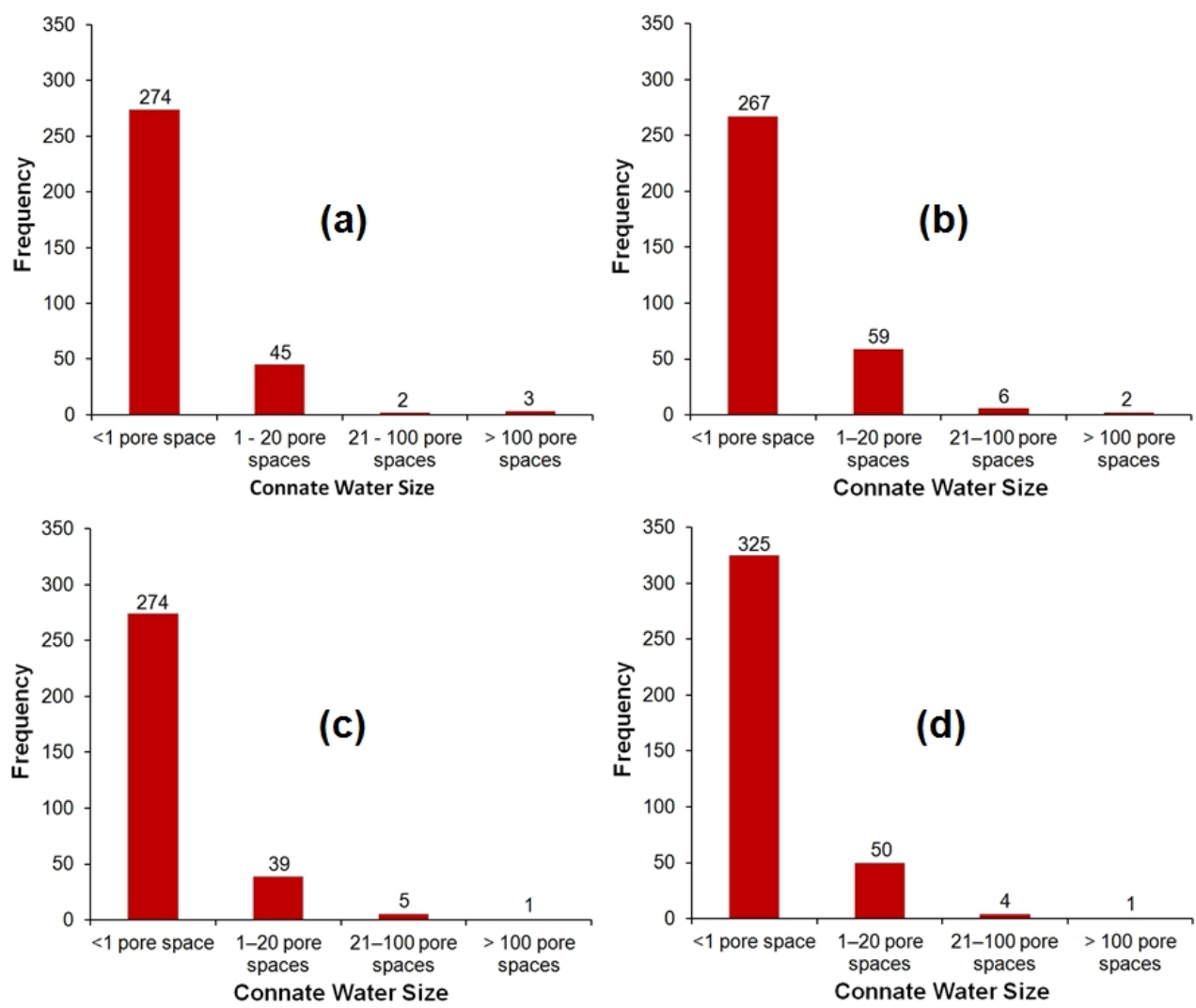

Fig. 7 Connate water sizes: (a) 0-2.5 mm, (b) 2.5-5 mm, (c) 5-7.5 mm, and (d) 7.5-10 mm.

Showing the important phenomena in certain position from three dimensional picture is very difficult. The position, thickness, and angle of view have to be set properly so that the important event will not be covered by unimportant event. Figure 6 shows water flooding in a porous medium without initial water saturation. The three dimensional images of the porous medium was evenly cut into four quadrants. One quadrant was selected to be shown in Fig. 6 . The glass beads and oil phase are digitally removed to show how water invades the porous medium more clearly. The blue region denotes injected water. The water displacement front is dominated by a large single structure of water as shown 
in Fig. 6a. Water invasion into a water-wet porous medium containing oil can be considered as imbibition. In imbibition, water tends to flow through the smallest channel since it has the highest capillary entrance pressure, which helps it to invade the pores. Water is less viscous and has lower density than oil. Theoretically this condition should create perturbation on the displacement front, thereby creating smaller water fingers. All of those factors affect the stability of the displacement front and water's path; therefore, we can see in Fig. $6 \mathrm{~b}$ that some oil was trapped. Fig. $6 \mathrm{~d}$ shows that water successfully invades most of the porous medium, leaving $24.67 \%$ of the oil behind. From visual inspection, steady state condition occurs when the 3D images from that time is absolutely same with the 3D images from previous time interval. It indicates that water cannot invade additional pore space other than the established channels.

For packed glass beads having diameters $400-600 \mu \mathrm{m}$ (average $500 \mu \mathrm{m}$ ), the average pore body size was $57.8 \mu \mathrm{m}$ (Al-Raoush and Willson, 2005). Pore body size for packed glass beads having diameters of $400 \mu \mathrm{m}$ was estimated to be $46.24 \mu \mathrm{m}$. A volume of one pore space was estimated to be $0.4143 \mu \mathrm{m}^{3}$. By dividing the observed pores into four sections from bottom to top, connate water is then divided by size as shown in Fig. 7.

Figure 7 shows the distribution of connate water in pores of various sizes along the observed area. Seven large connate water channels with volumes of more than 100 pore spaces dominate the entire connate water. These large channels are surrounded by more than a thousand connate water channels in dispersed form, each of which has a volume of less than 1 pore space. Some connate water channels with volumes of several pore spaces in a cluster of pores were also observed. From Fig. 7, we can see that the frequency distribution of connate water in various shapes along the pores is nearly even in each section.

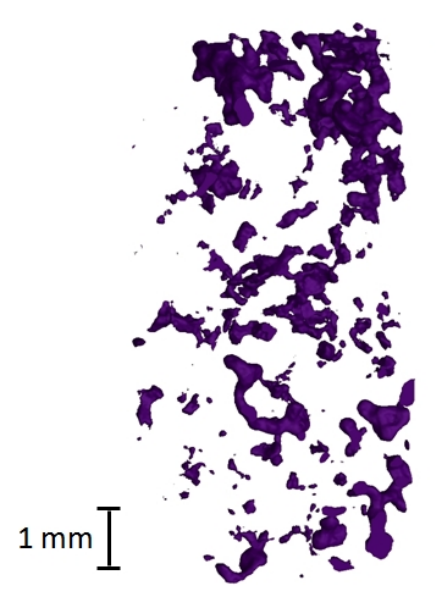

(a)

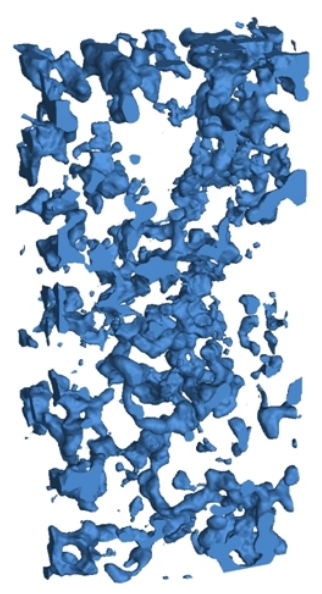

(b)

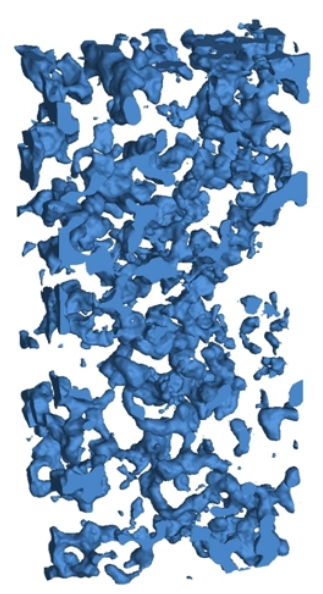

(c)

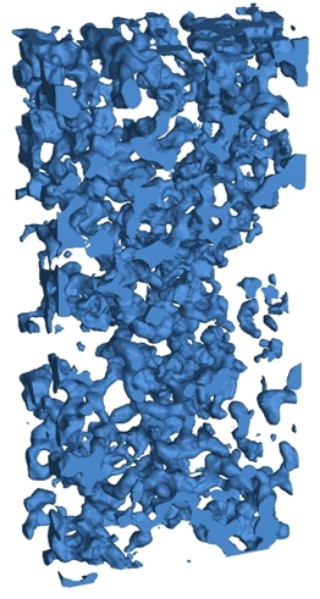

(d)

Fig. 8 Three-dimensional image of water flooding in porous medium with connate water: (a) initial condition, (b) injection of water for $5 \mathrm{~min}$, (c) injection of water for $10 \mathrm{~min}$, and (d) at steady state.

Figure 8 shows 3D images of water flooding in the porous medium with connate water. Three-dimensional porous media are very complicated structures. In order to show the effect of the presence of connate water on the development of water flow path during water flooding, $1 \mathrm{~mm}$ thick sections located in the middle of the tube was selected and shown in Fig. 8. Glass beads and the oil phase are also digitally removed. Purple and blue regions denote connate water and injected water during water flooding, respectively. Figure 8a shows the distribution of connate water along the observed area. Connate water exists in various forms and sizes.

In the beginning, the water invasion process has the same characteristics as that in the case of the porous medium without connate water; water tends to flow through the smallest channels in contact with the displacement front. Smaller channels provide higher capillary pressure, assisting spontaneous imbibition of water into pores occupied by oil. When injected water comes into contact with connate water, the displacement front rapidly expands into that space. In this way, the front suddenly jumps ahead. Connate water exists in various shapes and sizes. When injected water comes into contact with connate water contained in pore clusters or with a volume of 100 pore spaces, the displacement front creates a jump-like movement. It expands dramatically and creates a severe water finger. The only pressure difference inside the tube is between the inlet and outlet, where the inlet is connected to a syringe pump and the outlet is at atmospheric pressure. When injected water contacts connate water, the shape of the displacement front abruptly 
changes. Before the contact, connate water constitutes a discontinued phase that is trapped by the capillary pressures of surrounding pores. However, when the both types of water come into contact, they have a continuous phase. Pores around connate water that previously created capillary pressure, holding connate water in place, now become the only way for the water phase to flow. Because a pressure gradient exists in the axial direction only, water tends to flow through the upper most part of that connate water and not in the radial direction. This is also the reason why injected water appears to flow faster toward the outlet in porous media containing connate water as opposed to porous media without connate water. During this process, the shape of connate water containing pore volumes may deflect the movement of injected water as shown in Fig. 8b. When dispersed connate water with volumes less than 1 pore space contacts injected water, it accumulates but does not tend to deflect the water flow path. Once water breaks through, the pressure difference significantly decreases and the water tends to flow through the established path toward the outlet.

Figure $8 \mathrm{c}$ shows a water flow pattern after water flooding is conducted for $10 \mathrm{~min}$. The water phase that consists of connate water and injected water appears to grow thicker. In fact, it does not grow or expand radially because there is no pressure difference in that direction. The only reason the water channels thicken is that some other water fingers starting from the original location invade the channels next to the previous water finger so that it looks thicker. The water phase is slightly lighter and less viscous than the oil phase, because of which the displacement front tends to create many water fingers.

Figure $8 \mathrm{~d}$ shows the condition of the porous medium at steady state. We can see that some parts of the media are not invaded by water and oil is trapped. Deflection of the water flow path upon contact with connate water can disrupt continuity and trap oil. Comparing the oil recoveries in case of the porous medium without and with connate water, it is obvious that connate water reduces oil recovery significantly, as discussed in previous sections.

\subsection{Effect of Connate Water in Sweeping Efficiency and Distribution of Injected}

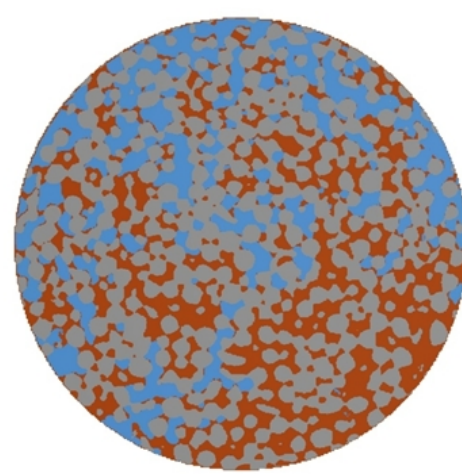

(a)

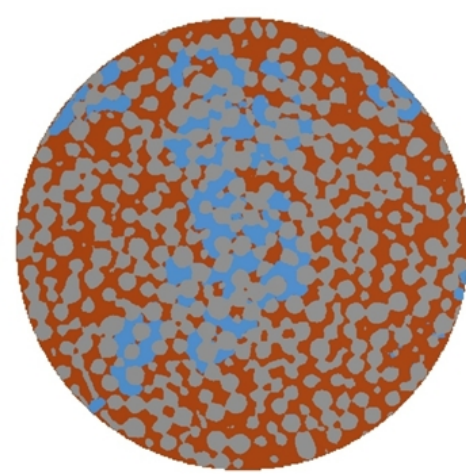

(b)

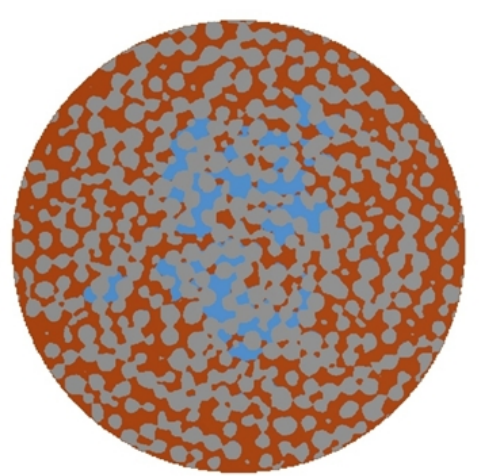

(c)

Fig. 9 Cross-sectional view of porous medium without connate water after water flooding for $5 \mathrm{~min}$ : (a) $0 \mathrm{~mm}$, (b) $5 \mathrm{~mm}$, and (c) $10 \mathrm{~mm}$ from the inlet.

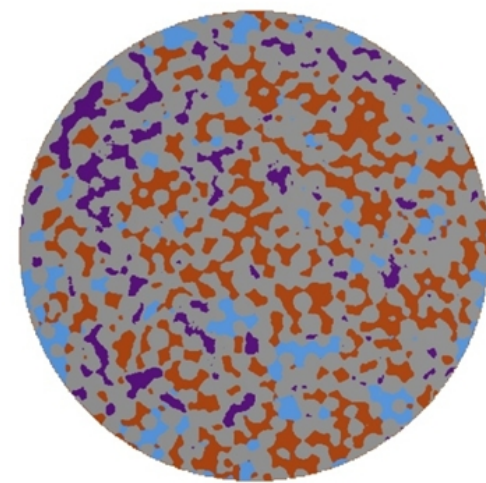

(a)

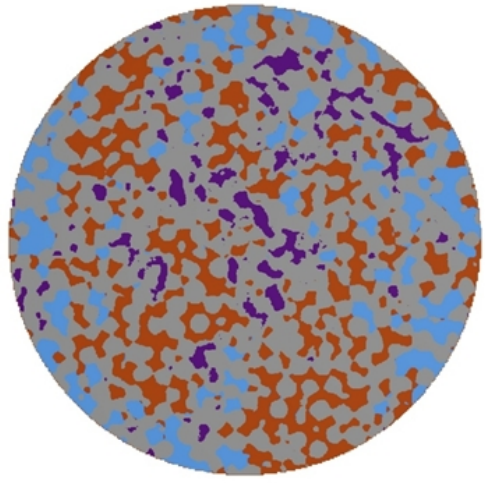

(b)

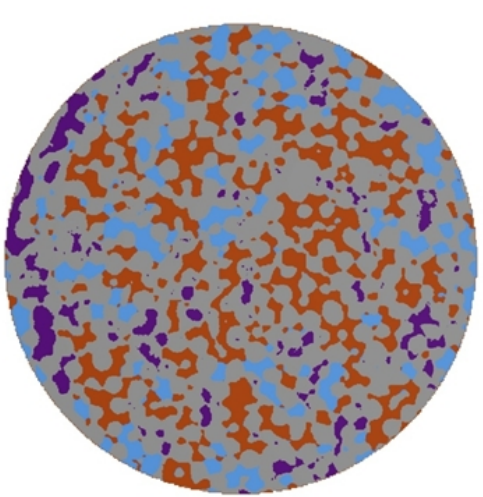

(c)

Fig. 10 Cross-sectional view of porous medium with connate water after water flooding for $5 \mathrm{~min}$ : (a) $0 \mathrm{~mm}$, (b) $5 \mathrm{~mm}$, and (c) $10 \mathrm{~mm}$ from the inlet. 
Grey, orange, blue and purple denote glass beads, oil, injected water, and connate water, respectively. At $0 \mathrm{~mm}$ from the bottom of the observed area, injected water invades not only the area previously occupied by connate water but also neighboring channels, as shown in Fig. 10a. In Fig 9a, water saturation is $57.25 \%$. In Fig. 10a, total area occupied by connate water and injected water is $47.78 \%$, which constitutes $26.37 \%$ connate water and $21.41 \%$ injected water. The water saturation in the porous medium without connate water is much larger than that in the porous medium with connate water. The existence of connate water reduces the growth of the area occupied by water, resulting in less sweeping area than in case of the porous medium without connate water, and this phenomenon is found even very close to the inlet.

At $5 \mathrm{~mm}$ from the bottom of the observed area, in case of the porous medium with connate water (Fig. 10b), saturation of injected water and connate water is $50.53 \%$, constituting $20.63 \%$ connate water and $29.9 \%$ injected water. Comparing with Fig. $9 \mathrm{~b}$, water saturation is only $27.58 \%$. At $5 \mathrm{~mm}$ from the bottom of the observed area, water saturation in the porous medium without connate water is actually less than in case of the porous medium with connate water.

At $10 \mathrm{~mm}$ from the bottom of the observed area, water saturation is $17.02 \%$ (Fig. 9c). Compared with Fig. 10c, the total water saturation is $38.03 \%$, constituting $23.4 \%$ connate water and $14.63 \%$ injected water. This indicates that most water in the porous medium without connate water remains in the lower part of tube, sweeping larger area. While in case of the porous medium with connate water, connate water helps injected water to flow faster so that it reaches and occupies larger area in upper areas of the tube after $5 \mathrm{~min}$ of water injection. When connate water is present, water flows faster toward the outlet. So instead of sweeping more area at the $0 \mathrm{~mm}$ position from the observed area, most water reaches $5 \mathrm{~mm}$ and $10 \mathrm{~mm}$ above it.

\section{Conclusions}

This study successfully investigated three dimensionally the pore-scale behavior of water flooding in a porous medium with and without the presence of connate water. In the porous medium without connate water, water flooding was able to produce $75.33 \%$ of the original oil; approximately 1.5 times more oil production than that in the case of the porous medium with connate water. Because of the steady interface movement, the local velocity of oil reduced gradually with time as the water invaded the pore space. The water displacement front was dominated by very large water fingers, leading to better displacement stability. This stable displacement causes water to sweep more area but travel less far at a given time compared with the case of water flooding in a porous medium with connate water.

When water flooding experiment was conducted in the porous medium with connate water, water not only flowed through preexisting connate water but also occupied neighboring pores. However, only $49.4 \%$ of the original oil was produced. When injected water came into contact with connate water contained in pore clusters or with a volume of more than 100 pore spaces, the displacement front suddenly expanded and moved to the end of the connate water channel, leaving the other water fingers behind. Because the pressure gradient was present only in the axial direction toward outlet, this expanding displacement front tended to select pores closest to the outlet. The consequent jump-like movement helped water move faster and reach the outlet earlier than that in the porous medium without connate water. Water breakthrough occurred faster so the local velocity of oil was dramatically reduced. The shape of connate water may also deflect the movement of injected water, creating oil entrapment.

\section{Acknowledgments}

This study was carried out in the JST Tokushima Plaza in The University of Tokushima.

\section{References}

Abramoff, M.D., Magelhaes, P.J., Ram, S.J., Image processing with image, Biophotonics International, Vol.11, No.7 (2004), pp.36-44.

Al-Raoush, R.I., Willson, C.S., A pore-scale investigation of a multiphase porous medium system, Journal of Contaminant Hydrology, Vol.77, No.1 (2005), pp. 67-89. 
Blunt, M.J., King, M.J., Simulation and theory of two-phase flow in porous medium. Physical Review A, Vol.46, No.12 (1992), pp.7680-7699.

Blunt, M.J., Scher, H., Pore-level modeling of wetting, Physical Review E, Vol.52, No.6 (1995), pp.6387-6403.

Chang, L.C., Tsai, J.P., Shan, H.Y., Chen, H.H., Experimental study on imbibition displacement mechanisms of two-phase fluid using micro model, Environmental Earth Sciences, Vol.59, No. 4 (2009), pp.901-911.

Fenwick, D.H., Blunt, M.J., Three-dimensional modeling of three phase imbibition and drainage, Advances in Water Resources, Vol.21, No.2 (1998), pp.121-143.

Goodfield, M., Goodyear, S.G., Townsley, P.H., New Coreflood Interpretation Method for Relative Permeabilities Based on Direct Processing In-Situ Saturation Data, The 2001 SPE Annual Technical Conference and Exhibition (2001), Paper No. SPE 71490.

Graue, A., Fernø, M.A., Aspenes, E., Needham, R., Wettability effects on water mixing during waterflood oil recovery, Journal of Petroleum Science and Engineering, Vol.94-95(2012), pp.89-99.

Graue, A., Fernø, M.A., Water mixing during spontaneous imbibition at different boundary and wettability conditions. Journal of Petroleum Science and Engineering, Vol.78, No.3-4 (2011), pp.586-595.

Jamaloei, B.Y., Asghari, K., Kharrat, R., Ahmadloo, F., Pore-scale two-phase filtration in imbibition process through porous medium at high- and low-interfacial tension flow condition, Journal of Petroleum Science and Engineering, Vol.72, No.3 (2010), pp.251-269.

Kang, Q., Zhang, D., Chen, S., Immicible displacement in a channel: simulations of fingering in two dimensions. Advances in Water Resources, Vol.27 (2004), pp.13-22.

Kestin, J., Sokolov, M., Wakeham, W.A., Viscosity of liquid water in the range $-8^{\circ} \mathrm{C}$ to $150^{\circ} \mathrm{C}$, Journal of Physical and Chemical Reference Data, Vol. 7, No.3 (1978), pp.941-948.

Kumar, M., Knackstedt, M.A., Senden, T.J., Sheppard, A.P., Middleton, J.P., Visualizing and quantifying the residual phase distribution in core material, Petrophysics, Vol.51, No.5 (2010), pp.323-332.

Morrow, N.R., Songkran, B., Effect of viscous and buoyancy forces on nonwetting phase trapping in porous medium. In: D. O. Shah (Ed.), Surface Phenomena in Enhanced Oil Recovery, Plenum Press (1981), pp. 387-411.

Paterson, L., Hornof, V., Neale, G.H., Water fingering into an oil-wet porous medium saturated with oil at connate water saturation, Institut Français du Pétrole, Vol.39, No.4 (1984), pp.517-521. 